\title{
Assessment of Distress with Physical and Psychological Symptoms of Patients in German Palliative Care Services
}

\author{
Karl Neuwöhner ${ }^{\mathrm{a}}$ Gabriele Lindena $^{\mathrm{b}}$ Team HOPE $^{\mathrm{c}}$ \\ aKlinik Dr. Hancken GmbH, Zentrum für Strahlentherapie, Hämato-Onkologie, Palliativmedizin, Stade, \\ ${ }^{\mathrm{b} C L A R A ~ K l i n i s c h e ~ F o r s c h u n g, ~ K l e i n m a c h n o w, ~ G e r m a n y ~}$ \\ ${ }^{\circ}$ Claudia Bausewein, Department of Palliative Care, Policy and Rehabilitation, King`s College London, UK; Petra Feyer, Vivantesklinikum \\ Neukölln, Berlin; Martin Fuchs, Bezirksärztekammer Rheinland-Pfalz; Ute Heinze, Medizinische Abteilung Mundipharma, Limburg; \\ Norbert Krumm, Klinikum RWTH Aachen; Friedemann Nauck, Universitätsklinik Göttingen; Christoph Ostgathe, Universitätsklinik \\ Erlangen; Anita Prescher, ISTO Deutsche Krebsgesellschaft, Berlin; Lukas Radbruch, Klinikum RWTH Aachen; Josef Ross, Pius-Hospital \\ Oldenburg, Germany
}

\section{Keywords}

Palliative medicine · Psycho-oncology · Distress screening

\section{Summary}

Background: Within the framework of the nationwide Hospice and Palliative Care Evaluation (HOPE), the German Basic Documentation for Psycho-oncology (PO-Bado) was used from 2004 to 2006 as an optional module in most participating palliative care services to investigate how patient distress due to symptom burdens in different palliative care settings should be assessed and how professional interventions could be derived. Patients and Methods: The distress scores of 3,317 PO-Bado records out of a total of 6,958 consecutive participants from 3 yearly samples of HOPE were evaluated descriptively and compared with a reference sample of cancer patients from both general and university hospitals. Results: The relative values of distress from physical and psychological symptoms were 0.57 and 0.37 (maximum of 1.0 ), respectively. In $38.2 \%$ of the patients, professional psychosocial interventions were indicated. Compared to the reference sample of cancer patients, palliative care patients clearly showed more specific physical distress, but psychological symptoms were varied; in particular, distress from cognitive impairment, helplessness and grief showed higher intensities in palliative care patients than in the reference group. Conclusions: The PO-Bado rating scales assessed high levels of distress, particularly from physical symptoms, in palliative care patients. A large percentage of palliative care patients required professional psychosocial support.

\section{Schlüsselwörter}

Palliativmedizin · Psychoonkologie · Distress-Screening

\section{Zusammenfassung}

Hintergrund: Im Rahmen der bundesweiten Hospiz- und Palliativerhebung HOPE wurde von 2004 bis 2006 die Psychoonkologische Basisdokumentation (PO-Bado) in den meisten teilnehmenden Institutionen als optionale Ergänzung eingesetzt, um festzustellen, wie die psychische Belastung der Patienten in Hospiz- und Palliativeinrichtungen eingeschätzt und wie daraus die Indikation für eine professionelle Intervention abgeleitet werden kann. Patienten und Methoden: Die Belastungsangaben in 3317 PO-Bado-Datensätzen von insgesamt 6958 Teilnehmern aus 3 jährlichen Stichproben der bundesweiten HOPE-Dokumentation wurden deskriptiv ausgewertet und mit Daten einer Referenzgruppe aus allgemein onkologischen Einrichtungen verglichen. Ergebnisse: Der relative Summenwert der Belastung durch somatische Symptome lag bei 0,57 (maximal 1), durch psychische Symptome bei 0,37 . Eine Indikation für eine professionelle psychosoziale Unterstützung wurde bei $38,2 \%$ der Patienten gesehen. Im Vergleich zu einer Referenzstichprobe von onkologischen Patienten zeigen Palliativpatienten deutlich stärkere körperliche Belastungen, während die psychischen Belastungen sich differenzieren: höher als in der Referenzgruppe waren die Belastungen durch kognitive Einschränkungen, Hilflosigkeit/Ausgeliefertsein und Trauer/Niedergeschlagenheit. Schlussfolgerungen: Die hohe psychische Belastung durch vor allem somatische Symptome wird bei Palliativpatienten in Deutschland mit Hilfe des PO-Bado-Moduls erfasst. Eine psychosoziale Unterstützung wird in vielen Fällen als notwendig angesehen.

\section{KARGER \\ Fax +497614520714 \\ Information@Karger.de}

www.karger.com (c) 2011 S. Karger GmbH, Freiburs

0378-584X/11/0343-0094\$38.00/0

Accessible online at:

www.karger.com/onk
Karl Neuwöhner

Klinik Dr. Hancken GmbH

Zentrum für Strahlentherapie, Hämato-Onkologie, Palliativmedizin

Harsefelder Str. 8, 21680 Stade, Germany

Tel. +49 4141 6041-31, Fax -78

neuwoehner@hancken.d 


\section{Introduction}

Distress and emotional strain are relevant to patients who are undergoing palliative and hospice care. Until recently, few studies have focused on specific psychosocial distress and comorbidity in patients with advanced cancer and terminal stages of diseases. For the most part, these studies referred to psychiatric diagnoses of mental disorders [1], while staff members in hospice and palliative care settings are faced with patients who experience the fear of pain, increasing dyspnoea, hopelessness, and grief and anxiety about burdening their families or relationship conflicts that are irresolvable in the short term. In general, these problems do not meet the criteria for psychiatric disorders according to ICD or DSM, but they do require professional interventions $[2,3]$. In common definitions of palliative care, the psychosocial support in addition to medical treatment is often highlighted as an important part of the 'holistic approach' of modern palliative medicine and palliative care institutions [4]. However, in a survey that included the majority of palliative care units in the German Hospice Directory [5], considerable differences were found in both symptom burden and supply [6]. In this study, we assessed the levels of emotional distress of in-patients and out-patients with standardised instruments and uniform rules. The study was performed as part of the yearly evaluation periods of the nationwide quality assurance project HOPE (Hospice and Palliative Care Evaluation). The following main topics were addressed: i) How much do palliative and hospice patients suffer from physical, psychological, and social symptoms compared to cancer patients in general hospitals and centres for rehabilitation? ii) How often is professional psychosocial support indicated among different services? iii) Is the basic documentation for psycho-oncology (PO-Bado) a reliable instrument to assess distress in palliative and hospice services? How does it compare to the HOPE core documentation? Does it add useful information to the HOPE core documentation?

\section{Patients and Methods}

Within the nationwide survey HOPE, which was established in 1999 by a working group of the German Association for Palliative Medicine and the German Cancer Society, the PO-Bado was offered as an add-on module during the evaluation period from 2004 to 2006. The PO-Bado form was applied with its expert ability to rate psychosocial stress at admission, while demographic, disease and stage-specific data were derived from the HOPE core documentation. Meetings were held to prepare the documentation period and written information with a specific manual and interview guidelines, but no specific training was provided for the application of the PO-Bado form.

\section{The HOPE Survey}

The German nationwide HOPE survey was based on a documentation period of up to 90 days per year [7]. In each service, up to 30 patients were documented consecutively. Starting in 2002, general oncology wards and hospices participated, and starting in 2004, medical practices and home care nursing services participated. The HOPE core documentation form includes demographic data, information about disease stage, and diagnoses (ICD or free text entry), co-morbidity, and the supply of care. Checklists for physical, nursing, and psychosocial symptoms and interventions were included, as were issues about the end of care. Symptom intensity was assessed with categorical scales (none, slight, moderate, severe). The HOPE core documentation forms were completed both at the time of admission and at the time of discharge, but staff members were also free to complete them weekly.

\section{Basic Documentation for Psycho-Oncology}

The PO-Bado was developed from 2000 to 2006 in collaboration with the German Association of Psycho-Social Oncology (DAPO) and the 'Arbeitsgemeinschaft für Psychosoziale Onkologie (PSO)' of the German Cancer Society, sponsored by German Cancer Aid. The psychometric validity of the PO-Bado was shown through correlations with the EORTC-Quality-of-Life-Questionnaire QLQ-C30, the Hospital Anxiety and Depression Scale (HADS), and the German Questionnaire on Stress in Cancer Patients (QSC-R23). The questionnaire contains demographic and psychosocial stress data, a manual with interview guidelines and a software application for statistical analyses, which consists of a database that includes more than 7,000 records from different settings (patients in different hospitals, cancer centres, and centres for rehabilitation). A standardised expert rating was prepared to assess psychosocial and additional stresses, the former using 5-point Likert scales, and the latter using 2-point ('Yes' vs. 'No') assessment scales. Three specific physical distress factors and a free text field were predefined. A sum score was calculated with a maximum of 16 points. A second sum score comprised 7 specific, predefined psychological distress factors and a free text field, with a maximum of 32 points. The rating was completed with the assessment of additional stressors related to social aspects and the indication for professional intervention [8].

\section{Data Analysis}

Sample homogeneity was examined by comparing demographic and medical data within the survey periods with t-tests and F-tests. Then the records from the optional PO-Bado module at admission were compared with a reference sample, collected from 2003 to 2006, which included 5,101 patients from oncology wards in general hospitals, cancer centres, and centres for rehabilitation (kindly provided by the aforementioned editors of the PO-Bado). This sample included and corresponded to published data of Herschbach et al. [9] but was used for this evaluation because it also differentiated between treatment settings and physical and psychological sum scores. To compare the physical and psychosocial loads of patients, the two total scores were converted to a $0-1$ relative scale that was independent from the number of items in question. For sum and relative scores, no missing data were accepted. The correlation of symptom distress in PO-Bado records with corresponding symptom intensity in HOPE core documentation at admission was calculated by Spearman's rank correlation. The severity of physical/psychosocial stress and awareness of the need for professional intervention were related to the care setting by a multivariate analysis. All statistical evaluations were performed using SPSS software (versions 17 and 18).

\section{Results}

A total of 6,958 patients were documented with the HOPE core documentation form within the evaluation period of 2004-2006, including 3,317 with the PO-Bado module (table 1). The number of patients differed between settings, as did the percentage with PO-Bado documentation (mean: 47.7\%; highest: $70.7 \%$ in inpatient palliative care wards; lowest: $31.1 \%$ in oncology wards). 


\section{Demographic and Medical Data at Admission}

\section{in Various Services}

With the exception of oncology wards, all services had a small majority of female patients. The mean age of the sample population was 67.4 years (standard deviation $(\mathrm{SD}) \pm 12.7$ ). The mean age did not differ for the subgroup of patients with PO-Bado assessments compared to all patients who were included in the HOPE survey and did not differ among the various services. The rates of patients with advanced cancer disease were similarly high in all services ( $90 \%$ or more), while the performance states differed characteristically (lowest in oncology wards, followed by medical practices, palliative inpatient care and homecare nursing services, and highest in hospices). The most frequent cancer diagnoses were those of the gastrointestinal (30\%) and respiratory (17\%) tracts, breast $(13.7 \%)$, female $(6.9 \%)$ and male $(6.2 \%)$ genital and urinary tract $(5.9 \%)$. Patients in palliative care wards $(9.5 \%)$ and medical practices $(10.2 \%)$ had significantly $(\mathrm{p}<0.000)$ more frequent diagnoses of mental disorders (ICD-10 chapter $\mathrm{V})$ than patients in hospices $(3.4 \%)$, oncology wards $(0.9 \%)$, or homecare nursing services. Data are shown in table 2.

\section{Comparison of Characteristics of the Patient and}

\section{Reference Groups}

The mean age of the reference sample was 10 years younger and had a higher percentage of females (70.9 versus $53.7 \%$ ) than those in the HOPE survey $(\mathrm{p}<0.000)$. Other significant differences were found for tumour stage and performance status. Distant metastases (TNM classification M $>0$ ) were documented for $29 \%$ of the reference group and $81 \%$ of the HOPE patients with PO-Bado records. The ECOG perform-

Table 1. Patients (number) assessed with PO-Bado module within the HOPE samples from 2004 to 2006 referring to services

\begin{tabular}{llll}
\hline Service & \multicolumn{2}{l}{ Patients } & \\
\cline { 2 - 4 } & $2004-2006, \mathrm{n}$ & HOPE total, $\mathrm{n}$ & PO-Bado, \% \\
\hline Palliative inpatient ward & 2,054 & 2,905 & 70.7 \\
Oncologic inpatient ward & 110 & 354 & 31.1 \\
Hospice & 533 & 965 & 55.2 \\
Medical practice & 443 & 805 & 55.0 \\
Home care service & 177 & 439 & 40.3 \\
Total & 3,317 & 6,958 & 47.7 \\
\hline
\end{tabular}

ance status [10] was rated as 3 (less than $50 \%$ of day time out of bed) for $13.2 \%$ and as 4 (completely bedridden) for $6.1 \%$ of the reference group compared to 34.3 and $38.9 \%$ of POBado HOPE patients, respectively.

\section{Distress Concerning Physical and Psychosocial Symptoms in Different Care Settings}

The highest distress values were reported for the physical symptoms 'restrictions in daily activities' and 'fatigue' and for the psychological symptoms 'helplessness' and 'anxiety/ worries'. Patient distress scores differed in different care settings (fig. 1). Distress related to physical symptoms was rated higher in all settings of the HOPE survey compared to the reference group. Distress from psychosocial symptoms related to 'cognitive impairment', 'helplessness', 'grief/depression', and 'shame' were found to be higher in specialised services such as palliative care inpatient units, hospices, and home care nursing services than in oncology wards or medical practices as well as in the reference group. Distress related to 'mood swings', 'anxiety/worries', and 'sleep disturbance' showed no differences among services or in the reference group. The sum score of distress related to psychological

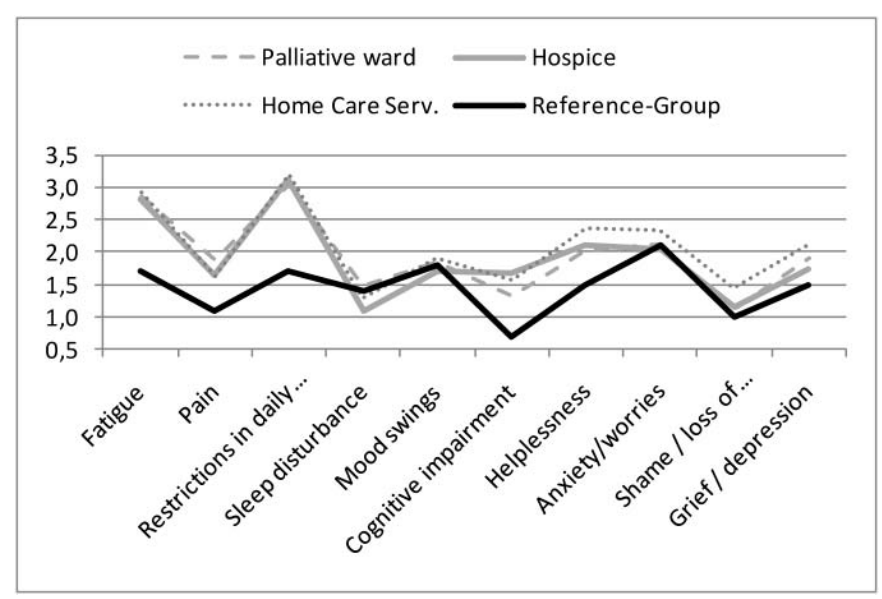

Fig. 1. Distress scores (mean from $0=$ 'does not suffer...' to $4=$ 'suffers seriously...') with regard to somatic and psychological symptoms referred to type of institution and reference sample; oncology units and medical practices showed lower distress scores from physical symptoms and were dropped for better visibility.

Table 2. Demographic and disease data of the PO-Bado sample $(n=3,317)$ compared to HOPE survey

\begin{tabular}{|c|c|c|c|c|c|c|c|}
\hline \multirow[t]{2}{*}{ Type of service } & \multicolumn{2}{|l|}{ Age } & \multirow[t]{2}{*}{ Female, \% } & \multicolumn{2}{|c|}{ ECOG, $\%$} & \multirow[t]{2}{*}{ Cancer disease, $\%$} & \multirow{2}{*}{$\begin{array}{l}\text { Distant metastases } \\
(\mathrm{M}>0), \%\end{array}$} \\
\hline & years $(M)$ & SD & & ECOG 3 & ECOG 4 & & \\
\hline Palliative inpatient ward & 67.0 & 12.4 & 53.5 & 36.4 & 38.6 & 95.1 & 83.6 \\
\hline Oncolog. inpatient ward & 65.8 & 10.3 & 35.2 & 39.4 & 4.6 & 98.2 & 88.2 \\
\hline Hospice & 69.8 & 13.5 & 59.1 & 36.0 & 54.7 & 89.7 & 75.4 \\
\hline Medical practice & 66.6 & 13.4 & 53.7 & 21.0 & 31.1 & 95.9 & 75.4 \\
\hline Home care service & 67.1 & 11.6 & 50.8 & 34.3 & 37.9 & 91.0 & 76.8 \\
\hline Total $(\mathrm{n}=3,317)$ & 67.4 & 12.7 & 53.7 & 34.3 & 38.9 & 94.2 & 81.0 \\
\hline HOPE-survey $(\mathrm{n}=6,958)$ & 67.4 & 12.7 & $53.8^{\mathrm{a}}$ & 33.8 & 40.6 & 93.4 & 80.9 \\
\hline Reference group & 57.5 & 13.8 & 70.9 & 13.2 & 6.1 & 100.0 & 29.0 \\
\hline
\end{tabular}


symptoms had a relative score of 0.37 and was approximately one third lower than the sum score of distress related to physical impairments, which had a score of 0.57 . In patients who were cared for until their death, the sum scores were as high as 0.44 (psychological symptoms) and 0.66 (physical symptoms).

\section{Additional Stress Factors and Indications for Professional Psychosocial Support}

Approximately one third of the patients stated that their distress was related to problems with family and friends. One quarter of the patients explained that independent stress factors that were unrelated to their diseases were relevant. Both of these stress factors showed considerable differences among the various settings. An indication for professional psychosocial support was documented for $38.2 \%$ of patients. The indication was established more often for patients with higher distress scores that were related to psychological symptoms compared to those with lower scores (fig. 2), but there were significant differences among settings. Oncology wards ascertained the need for professional intervention for distress from psychological symptoms by a mean total score of 0.39 , palliative care units by a mean score of 0.47 , and hospices by a mean score of 0.55 (fig. 2). Of patients who had diagnoses of mental disorders (ICD-10 chapter V) (258, or $7.8 \%$ ), 41 received indications for professional support. The indications were more closely related to setting than to gender, total score, or ECOG performance status.

\section{Correlations Between the Symptom Checklists of the HOPE} Core Documentation Form and the PO-Bado Assessment The symptom checklist of the HOPE core documentation form assesses the intensity of physical and psychological symp-

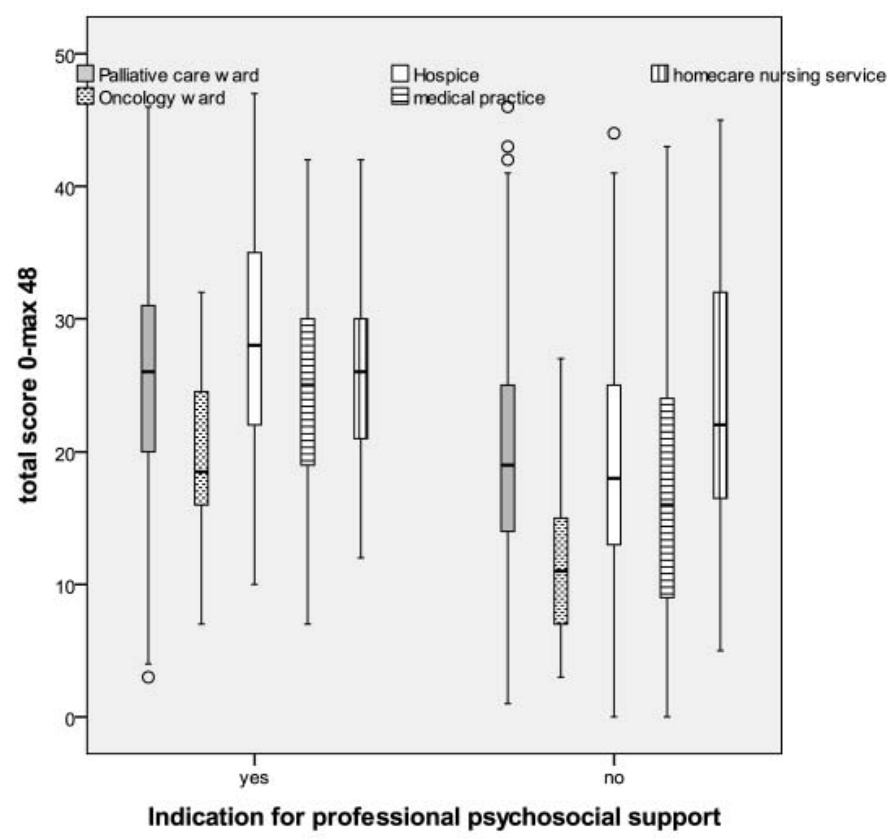

Fig. 2. Total distress score and need for professional intervention ('yes'/'no') as seen by the settings; box: median and 25/75 quartiles, whiskers $90 \%$, circles extreme values. toms using an external rating. The PO-Bado questionnaire explores patients' subjective experiences using expert rating scales; thus, neither instrument is self-rated. Some items showed significant Pearson correlation coefficients, including 'subjective burden of pain' in PO-Bado with 'pain intensity' in HOPE (0.651), 'fatigue' with 'weakness' (0.502) and 'tiredness' (0.460), 'restrictions in daily activities' with 'need for help' (0.477), and 'anxiety/worries' with 'fear' (0.553) and 'tenseness' (0.534). All other correlations of single symptoms were lower than these values. The correlation of the total score (PO-Bado) with the total symptom load (HOPE) was significant but not congruent (0.581). Gender and age were not correlated with the total score, but ECOG performance status was correlated with higher distress scores in dying patients.

\section{Discussion}

This study presents for the first time a systematic survey on the subjective experiences of a large number of patients in a large number of palliative care services in different settings. In combination with descriptions of symptom intensity from the results of the HOPE core documentation form, the POBado records provide a rich source of information about the physical and emotional aspects of palliative care patients.

Patients experienced 'fatigue' and other physical disabilities and intense 'restrictions in daily activities' as particularly distressing. Similarly, Krumm et al. [11] emphasised physical disabilities as major distress factors. Our results illustrate the increased distress load from exacerbated physical problems of palliative patients with advanced diseases, including a majority of cancer diagnoses, compared to cancer patients in the reference group, who were less advanced in their disease trajectories.

'Helplessness' was the psychological symptom that induced the most distress, particularly with regard to the increased need for care. 'Anxiety/worries' were also related to high distress scores in patients facing death. Distress scores from psychological symptoms were one third lower than the scores related to physical symptoms. However, this difference might be related to symptom clusters [12] which might include psychological symptoms such as anxiety and depression as well as physical symptoms [13]. The high burden of the PO-Bado total score in palliative care patients has already been shown by Herschbach et al. [8], but the difference between the physical loads of palliative care patients and those of the reference group could explain the main differences shown in the total scores (fig. 1).

On average, patients in the PO-Bado/HOPE survey were 10 years older than patients in the reference group. The patients of the HOPE survey suffered from typical problems related to advanced disease, predominantly functional impairment and the need for nursing support [14]. The profile of distress factors included in the PO-Bado accurately describes patients receiving palliative care. 
The correlation analysis showed an expected mismatch between symptom intensity, as assessed by the HOPE core documentation, and distress, as assessed by the PO-Bado score, even when the same terms (i.e. 'pain') were used. The difference between symptom intensity and the subjective experience of distress has already been established $[15,16]$. If an evaluation of patient experiences is required (benefiting from an expert rating), then the results of the HOPE core documentation form need to be supplemented with information from the PO-Bado. The noted differences between symptom intensity and distress factors have an impact on clinical decision making for treatment and symptom control.

Within the PO-Bado questionnaire, the therapeutic consequences that may arise from patients' personal experiences and those of their caregivers are implicated only in the final question: whether professional psychosocial support is indicated. According to guidelines [17], the editors of the POBado specify 'professional psychosocial support' as a minimum of one contact by a social worker, therapist, or physician with special qualifications, who can assess whether an improvement in the patient's quality of life by psycho-oncologic therapy is expected or whether a specific psycho-oncologic examination is required for clarification [18]. The German Cancer Society currently recommends the PO-Bado as a screening instrument to assess the requirement for professional psycho-oncologic support [19].

\section{Conclusions}

The results of the PO-Bado records provided information on specific distress types that were related to the symptoms of patients receiving palliative care. The distress profile differed from the reference data of the PO-Bado in general oncology wards, as patients in palliative care settings are often more advanced in their disease trajectories, are older, are more impaired, and have greater nursing needs. There was only slight evidence of correlations between symptom intensity according to the HOPE core documentation and subjective distress experiences according to PO-Bado scores. Services were shown to advance the indication for professional psychosocial support at different severities and time points, e.g. occurring with the highest severity in hospices; these differences may depend on the availability of appropriate staff members. Potential under-recognition and underassessment of distress in several services may be caused by a mistaken 'holistic' concept. In fact, staff members in palliative and hospice care services are not released from detecting and attending to patients' psychosocial needs, but in this sample, almost $40 \%$ of the interviewed patients needed specialised psychosocial support, even if their distress was predominantly related to their physical symptoms. Hospice and palliative care services should generate common standards for supplying psychosocial support, similar to those of certified cancer centres [20]. For this purpose, the PO-Bado could be a very useful instrument.

\section{Acknowledgements}

The authors would like to thank the participating services for their studious documentations. Funding was provided by MUNDIPHARMA, Germany, for the HOPE survey and by the German Cancer Aid for the PO-Bado.

\section{Disclosure Statement}

The authors declare that they have no competing interests.

\section{References}

1 Miovic M, Block S: Psychiatric disorders in advanced cancer. Cancer 2007;110:1665-1676.

2 Mehnert A, Lehmann C, Koch U: Prävalenz und Diagnostik psychischer Störungen in der Onkologie. Der Onkologe 2006;12:18-26.

3 Weis J, Schumacher A, Blettner G, Determann M, Reinert E, Rüffer JU, Werner A, Weyland P: Psychoonkologie - Konzepte und Aufgaben einer jungen Fachdisziplin. Der Onkologe 2007;13:185-194.

4 Pichelmaier H: Palliativmedizin. Dt. Ärzteblatt 1998;95:1964-1965.

5 Radbruch L, Nauck F, Sabatowski R: Wegweiser Hospiz und Palliativmedizin Deutschland 2008; www.wegweiser-hospiz-palliativmedizin.de.

6 Nauck F, Radbruch L, Ostgathe C, Fuchs M, Neuwöhner K, Schulenberg D, Lindena G: Kerndokumentation für Palliativstationen. Strukturqualität und Ergebnisqualität. Z Palliativmed 2002;3:41-49.

7 Lindena G, Nauck F, Bausewein C, Neuwöhner K, Heine O, Schulenberg D, Radbruch L: Qualitätssicherung in der Palliativmedizin - Ergebnisse der Kerndokumentation 1999-2002. Z Ärztl Fortbild Qual Gesundh wes 2005;99:555-565.

$\checkmark$ Herschbach P, Book K, Brandl T, Keller M, Marten-Mittag B: The Basic Documentation for Psy-
cho-Oncology (PO-Bado) - an expert rating scale for the psychosocial experience of cancer patients. Onkologie 2008;31:591-596.

9 Herschbach P, Book K, Brandl T, Keller M, Lindena G, Neuwöhner K, Marten-Mittag B: Psychological distress in cancer patients assessed with an expert rating scale. Br J Cancer 2008;99:37-43.

10 Oken MM, Creech RH, Tormey DC, Horton J, Davis TE, McFadden ET, Carbone PP: Toxicity and response criteria of the Eastern Cooperative Oncology Group. Am J Clin Oncol 1982;5:649-655.

11 Krumm N, Stiel S, Ostgathe C, Lindena G, Nauck F, Elsner F, Radbruch L, und die Koordinierungsgruppe HOPE: Subjektives Befinden bei Palliativpatienten - Ergebnisse der Hospiz- und Palliativerhebung (HOPE). Z Palliativmed 2008;9:132-138.

12 Cheung, WY, Le WL, Zimmermann C: Symptom clusters in patients with advanced cancer. Support Care Cancer 2009;17:1223-1230.

13 Delgado-Guay M, Parsons HA, Li Z, Palmer JL, Bruera E: Symptom distress in advanced cancer patients with anxiety and depression in the palliative care setting. Support Care Cancer 2009;17:573-579.

14 Walsh D, Donelly S, Rybicki L: The symptoms of advanced cancer: relationship to age, gender, and performance status. Support Care Cancer 2000;8:175-179.

15 Broberger E, Tishelman C, von Essen L, Doukkali E, Sprangers MA: Spontaneous reports of most distressing concerns in patients with inoperable lung cancer: at present, in retrospect and in comparison with EORTC-QLQ-C30+LC13. Qual Life Res 2007;16:1635-1645.

16 Tishelman C, Petersson LM, Degner LF, Sprangers MA: Symptom prevalence, intensity, and distress in patients with inoperable lung cancer in relation to time of death. J Clin Oncol 2007;25:5381-5389.

17 Mehnert A, Petersen C, Koch U: Empfehlungen zur Psychoonkologischen Versorgung im Akutkrankenhaus. Z Med Psychol 2003;12:77-84.

18 Herschbach P: PO-Bado online manual; www.pobado.med.tu-muenchen.de/pdf/; Standard-Version/ Manual_PO-Bado_2,2009.pdf; 2009.

19 Herschbach P, Weiss J (ed): Screeningverfahren in der Psychoonkologie - Testinstrumente zur Identifikation betreuungsbedürftiger Krebspatienten. Berlin 2008.

20 Koch-Gromus U, Mehnert A: Psychoonkologie und Versorgungsforschung. Forum Deutsche Krebsgesellschaft 2009;24:44-47 